\title{
Serum carotenoid and retinol levels in African-Caribbean Tobagonian men with high prostate cancer risk in comparison with African-American men
}

\author{
Alicia C. McDonald ${ }^{1 *}$, Clareann H. Bunker ${ }^{2}$, Jay Raman ${ }^{3}$, John Richie ${ }^{1}$ and Alan L. Patrick ${ }^{4}$ \\ ${ }^{1}$ Department of Public Health Sciences, Pennsylvania State University College of Medicine, Hershey, PA 17033, USA \\ ${ }^{2}$ Department of Epidemiology, University of Pittsburgh, Pittsburgh, PA 15261, USA \\ ${ }^{3}$ Department of Surgery, Pennsylvania State University College of Medicine, Hershey, PA 17033, USA \\ ${ }^{4}$ Tobago Health Studies Office, Scarborough, Tobago, Trinidad and Tobago \\ (Submitted 5 August 2016 - Final revision received 10 March 2017 - Accepted 24 March 2017- First published online 11 May 2017)
}

\section{Abstract}

Black men are known to have a higher risk for prostate cancer (PC). Carotenoids and retinol, linked to PC, have not been compared in different black populations at risk. We examined serum carotenoid and retinol levels between PC-free African-Caribbean (AC) Tobagonian men with a high PC risk (high-grade prostatic intraepithelial neoplasia, atypical foci or repeated abnormal PC screenings) and African-American (AA) men with elevated serum prostate-specific antigen (PSA) levels $(\geq 4 \mathrm{ng} / \mathrm{ml}$ ). AC men who participated in the 2003 lycopene clinical trial and AA men who participated in the 2001-2006 National Health and Nutrition Examination Survey were compared. Serum specimens were analysed for carotenoid ( $\beta$-carotene, $\alpha$-carotene, $\beta$-cryptoxanthin, lutein/zeaxanthin and lycopene) and retinol levels by isocratic HPLC. Quantile regression was used to examine the association between serum carotenoid and retinol levels and black ethnicity, overall and among men with elevated serum PSA. There were sixty-nine AC men and sixty-five AA men, aged 41-79 years, included. AC men were associated with lower serum lycopene and retinol levels, and higher serum $\alpha$ - and $\beta$-carotenes and lutein/zeaxanthin levels compared with AA men, after adjusting for age, BMI, ever smoked cigarettes, education and hypertension $(P \leq 0 \cdot 03)$. Among men with elevated PSA, serum retinol was no longer statistically significant with ethnicity $(P=0 \cdot 06)$. Possible differences may be attributed to dietary intake, genetics and/or factors that influence bioavailability of these micronutrients. Prospective studies are warranted that investigate whether these differences in micronutrients between AC Tobagonian and AA men influence PC risk.

Key words: Carotenoids: Retinol: African-Caribbean men: African-American men: Prostate cancer

Prostate cancer is the second most common cancer and the fifth leading cause of cancer death in men worldwide ${ }^{(1)}$. AfricanAmerican (AA) men and African-Caribbean (AC) men are known to have the highest prostate cancer incidence rates compared with other racial groups ${ }^{(2)}$. Men from the Caribbean have been reported to have the highest prostate cancer mortality worldwide ${ }^{(1)}$. Black race, older age and family history of prostate cancer are known risk factors for prostate cancer. Genetic susceptibility and alterations, chronic inflammation, and diet are possible risk factors for this disease. Dietary intake and high circulating levels of carotenoids and retinol (vitamin A) have been linked to a decreased risk of prostate cancer ${ }^{(3-7)}$. However, associations between these micronutrients and prostate cancer risk remain inconclusive because of conflicting study results ${ }^{(3,5,7-10)}$.

Carotenoids, which are natural pigments, and retinol are found in certain fruits and vegetables. Studies suggest that these micronutrients may influence prostate cancer risk and progression because of their antioxidant abilities in reducing oxidative stress $^{(8)}$, a factor which is believed to play a role in the initiation and progression of cancers ${ }^{(7,11)}$. There are six major dietary carotenoids ( $\beta$-carotene, $\alpha$-carotene, $\beta$-cryptoxanthin, lutein, lycopene and zeaxanthin). Lycopene, which is the most well studied in prostate cancer, is considered the most potent carotenoid because of its quenching singlet $\mathrm{O}_{2}$ and free radical scavenging abilities ${ }^{(7,12-14)}$. Retinol and its carotenoid precursors ( $\alpha$-carotene, $\beta$-carotene and $\beta$-cryptoxanthin), also known as provitamin A carotenoids, have been found to be important in processes that influence carcinogenesis such as cell growth, differentiation and apoptosis ${ }^{(5,15)}$. Because of their antioxidant and provitamin A activities, higher dietary intake or circulating levels of these micronutrients may play a role in reducing prostate cancer risk and preventing prostate cancer progression.

For the Caribbean island of Tobago, an overall prostate cancer screening prevalence of $11 \%$ ( $n$ 342/3089) was found among men, aged 40-79 years, in the Tobago Prostate Survey $^{(16)}$, a population-based, longitudinal prostate cancer

Abbreviations: AA, African-American; AC, African-Caribbean; DRE, digital rectal examination; HGPIN, high-grade prostatic intraepithelial neoplasia; NHANES, National Health and Nutrition Examination Survey; PSA, prostate-specific antigen.

* Corresponding author: A. C. McDonald, fax +1 717531 0480, email amcdonal@phs.psu.edu 
screening study in which $92 \%$ of men are of African descent ${ }^{(17)}$. From this screening survey, Tobagonian men were found to have a higher age-specific prevalence of prostate cancer ( $1 \%$ aged $40-49$ years to $29 \%$ aged $70-79$ years $)^{(16)}$ compared with white American men ( $0.05 \%$ aged $40-49$ years to $8.7 \%$ aged $70-79$ years) and AA men ( $0 \cdot 14 \%$ aged $40-49$ years to $13 \cdot 0 \%$ aged 70-79 years) from the National Cancer Institute Surveillance, Epidemiology, and End Results Program (SEER) based on 2002 prostate cancer prevalence ${ }^{(18)}$. The reasons for the difference in prostate cancer prevalence between Tobagonian and American men, in particular, AA men, are not known. On the basis of the reported prostate cancer prevalence among Tobagonian and AA men, we hypothesised that AC Tobagonian men will have lower serum carotenoid and retinol levels in comparison with AA men. To test this hypothesis, we examined the distribution of serum carotenoid and retinol levels in $\mathrm{AC}$ Tobagonian men who were prostate cancer free but had a high prostate cancer risk and compared their levels with AA men who participated in the 2001-2006 National Health and Nutrition Examination Survey (NHANES).

\section{Methods}

\section{Study design and study population}

We conducted a cross-sectional study to describe serum carotenoid ( $\beta$-carotene, $\alpha$-carotene, $\beta$-cryptoxanthin, lycopene and lutein/zeaxanthin) and retinol levels among AC Tobagonian men, aged 40-79 years, who were considered to be at high-risk for prostate cancer compared with AA men, aged 40-79 years, with elevated serum prostate-specific antigen (PSA) in the US general population. AC Tobagonian men were drawn from the Tobago Prostate Survey ${ }^{(17)}$ who were participants in the randomised, Phase I, lycopene supplementation clinical trial conducted in August $2003^{(19)}$. Tobagonian men were included if they had conditions considered at high-risk for subsequent prostate cancer diagnosis: high-grade prostatic intraepithelial neoplasia (HGPIN), atypia (atypical small acinar proliferation), or persistently elevated serum PSA ( $\geq 4 \mathrm{ng} / \mathrm{ml}$ ) and/or abnormal digital rectal examination (DRE) at two study visits before randomisation. Additional inclusion and exclusion criteria were described previously ${ }^{(19)}$. In the present study, AC Tobagonian men were excluded if they had biopsy-confirmed prostate cancer before randomisation or within 1 year after randomisation. Demographic information (age, race, marital status and educational status), lifestyle behaviour (ever smoked cigarettes), medical history (diabetes, CHD and hypertension) and family history of prostate cancer were extracted from the Tobago Prostate Survey questionnaires. Clinical information such as serum PSA, DRE results and biopsy results were obtained from laboratory results, physical examination and pathology reports, respectively, before randomisation. BMI $(\mathrm{kg} /$ $\mathrm{m}^{2}$ ) was measured at randomisation. Blood samples were collected at randomisation to test for serum carotenoid and retinol levels and serum PSA. An FFQ was used to measure in-season and out-of-season dietary lycopene intake, as described elsewhere ${ }^{(19)}$.

AA men were drawn from the 2001-2006 US population-based survey NHANES, which collects health and nutritional information from a non-institutionalised, nationally representative sample of the US population. Men were excluded if they have or had cancer (including prostate cancer) at the time of enrolment, had no serum carotenoid or retinol laboratory data, or had missing serum PSA data. Men were included if they were of African descent and had an elevated serum PSA. HGPIN, atypia and abnormal DRE results were not collected from men who participated in NHANES. Demographic information, lifestyle behaviour, medical history and family history of prostate cancer were collected from interviewer-administered questionnaires. BMI was measured. Blood samples were collected and laboratory tests were performed to examine serum carotenoid, retinol and PSA levels. The average daily dietary intake of carotenoids based on the daily total nutrient intake consumed by the participant was determined from a 24-h dietary recall survey given on 2 separate days, except for the 2001-2002 NHANES participants for whom the survey was administered once.

All study participants signed an informed consent form. The Tobago study was approved by the Institutional Review Board of the Division of Health and Social Services, Tobago House of Assembly and the Institutional Review Board of the University of Pittsburgh. The 2001-2006 NHANES was approved by the Research Ethics Review Board of the National Center for Health Statistics. This study was conducted in accordance with The Declaration of Helsinki's ethical standards.

\section{Laboratory methods}

Blood samples from AC Tobagonian men were shielded from light during clot formation. For both groups of men, blood samples were separated by centrifugation to obtain serum. For AC Tobagonian men, total serum PSA laboratory results obtained from the clinical trial were used in the present study's analyses. Total serum PSA was determined by an automated AxSYM assay system (Abbott Laboratories) conducted at the University of Pittsburgh Medical Center Clinical Pathology Laboratory. For AA men, total serum PSA was determined using the Access Hybritech PSA assay (Beckman Coulter, Inc.). Serum carotenoid and retinol levels were measured by an isocratic HPLC procedure conducted by Genox Corporation and Craft Technologies, Inc. for AC and AA men, respectively. The isocratic HPLC procedure was standardised using the Standard Reference Material (SRM) for fat-soluble vitamins provided by the National Institute of Standards and Technology. For Tobagonian men, a CV of $8.3 \%$ for the serum carotenoid and retinol levels was calculated between duplicates of nine study participants, approximately $12 \%$ of the clinical trial study population. For the NHANES study population, a CV of $\leq 5.5 \%$ for serum carotenoid and retinol levels was calculated among 200 or 221 samples, except for serum zeaxanthin, which had a CV as high as $13.4 \%$ for one $\operatorname{lot}^{(20)}$.

\section{Data analysis}

Pearson's $\chi^{2}$ test, Fisher's exact test or the Mann-Whitney test was used to examine whether there were any differences in study characteristics listed in Table 1 between AC Tobagonian and AA men. Serum carotenoid and retinol levels measured in $\mu \mathrm{g} / \mathrm{dl}$ among AA men were converted into $\mu \mathrm{g} / \mathrm{ml}$ by dividing by 100 , and dietary intake of lycopene measured in $\mu \mathrm{g}$ among AA 
men was converted into mg by dividing by 1000 , the same unit used in AC Tobagonian men. Median serum carotenoid and retinol levels, dietary lycopene intake (the only dietary intake information available for both groups of men) and their 25th-75th percentiles were calculated, and the Mann-Whitney test was used to examine whether there were differences in these levels for the following groups: (1) AC Tobagonian men with HGPIN, atypia and/or persistently elevated serum PSA and/or abnormal DRE $v$. AA men with elevated serum PSA, and (2) AC Tobagonian men with elevated serum PSA $v$. AA men with elevated serum PSA. Spearman's correlation coefficient $\left(r_{\mathrm{s}}\right)$ was calculated to examine the relationship between dietary lycopene intake and serum lycopene levels for both groups of men. Within both groups of men, median serum carotenoid and retinol levels were examined by covariates such as age (40-49, 50-59, 60-69, and 70-79 years), BMI (underweight/ normal $\left(<25 \mathrm{~kg} / \mathrm{m}^{2}\right)$, overweight $\left(25-29 \cdot 9 \mathrm{~kg} / \mathrm{m}^{2}\right)$ and obese $\left(\geq 30 \mathrm{~kg} / \mathrm{m}^{2}\right)$ ), ever smoked cigarettes (yes or no), and other study variables found statistically significant in Table 1 . The ever smoked cigarettes variable was defined by $>6$ months of cigarette smoking for Tobagonian men and smoking $\geq 100$ cigarettes for NHANES men. Quantile regression or the Mann-Whitney test was used to examine whether there was a statistically significant difference in median serum carotenoid and retinol levels for covariates. Quantile regression was used to examine whether serum carotenoid and retinol levels were associated with ethnicity (AC Tobagonian men compared with AA men), after adjusting for confounding factors. Data analysis was conducted at $\alpha$ level 0.05 in SAS version 9.2.

\section{Results}

A total of sixty-nine AC Tobagonian men, aged 43-78 years, and sixty-five AA men, aged 41-79 years, were included in the final analysis. AC Tobagonian men were statistically significantly younger, less likely to have graduated from high-school and less likely to have hypertension compared with AA men as shown in Table $1(P \leq 0 \cdot 01)$. There was no difference in BMI, marital status, ever smoked cigarettes, diabetes, CHD, family history of prostate cancer, and elevated serum PSA between the two groups.

Compared with AA men, AC Tobagonian men had statistically significantly lower levels of serum lycopene, retinol, and $\beta$-cryptoxanthin, and statistically significantly higher levels of serum $\alpha$ - and $\beta$-carotenes and lutein/zeaxanthin $(P<0 \cdot 02)$ (Fig. 1). Among men with elevated serum PSA, these statistically significant relationships of serum carotenoids remained between AC Tobagonian and AA men, except for serum $\beta$-cryptoxanthin where no difference in median levels was observed (Fig. 2). As for the estimated daily dietary lycopene intake, AC Tobagonian men overall (median $=9.6 \mathrm{mg} / \mathrm{d} ; n 69$, 25th-75th percentile: $5 \cdot 2-15 \cdot 2 \mathrm{mg} / \mathrm{d}$ ) and AC Tobagonian men with elevated PSA only (median $=7.5 \mathrm{mg} / \mathrm{d} ; n$ 36, 25th-75th percentile: $2.9-14.5 \mathrm{mg} / \mathrm{d}$ ) had higher dietary lycopene intake compared with AA men with elevated PSA (median $=2.2 \mathrm{mg} / \mathrm{d}$; $n$ 35, 25th-75th percentile: $0.42-6.66 \mathrm{mg} / \mathrm{d})(P<0.01)$. The Spearman's correlation coefficient $\left(r_{\mathrm{s}}\right)$ between dietary lycopene intake and serum lycopene level was $0 \cdot 15$ for $\mathrm{AC}$ Tobagonian men $(P=0.21)$ and 0.58 for AA men $(P<0.01)$.
Table 1. Study characteristics of African-Caribbean (AC) Tobagonian men and African-American (AA) National Health and Nutrition Examination Survey (NHANES) men

(Medians and ranges; medians and 25th-75th percentiles; frequencies)

\begin{tabular}{|c|c|c|c|}
\hline Characteristics & $\begin{array}{c}\text { AC } \\
\text { Tobagonian } \\
\text { men }(n 69)\end{array}$ & $\begin{array}{c}\text { AA } \\
\text { NHANES } \\
\text { men }(n 65)\end{array}$ & $P$ \\
\hline Age (years) & & & $<0.01$ \\
\hline Median & 62 & 66 & \\
\hline Range & $43-78$ & $41-79$ & \\
\hline BMI $\left(\mathrm{kg} / \mathrm{m}^{2}\right)$ & $n 69$ & $n 64$ & \\
\hline Median & $26 \cdot 9$ & $26 \cdot 9$ & $0 \cdot 75$ \\
\hline 25th-75th percentile & $24 \cdot 7-29 \cdot 1$ & $24 \cdot 1-31 \cdot 0$ & \\
\hline Education (\%)* & $n 69$ & $n 65$ & $<0.01$ \\
\hline$\leq 11$ years & $75 \cdot 4$ & $50 \cdot 8$ & \\
\hline$\geq 12$ years & $24 \cdot 6$ & $49 \cdot 2$ & \\
\hline Ever married/lived as married (\%) & $n 69$ & $n 65$ & 0.90 \\
\hline No & $13 \cdot 0$ & $12 \cdot 3$ & \\
\hline Yes & $87 \cdot 0$ & $87 \cdot 7$ & \\
\hline Ever smoked cigarettes (\%) & $n 69$ & $n 65$ & 0.06 \\
\hline No & $58 \cdot 0$ & 41.51 & \\
\hline Yes & $42 \cdot 0$ & $58 \cdot 5$ & \\
\hline Diabetes (\%) & $n 67$ & $n 65$ & 0.44 \\
\hline No & $85 \cdot 1$ & $80 \cdot 0$ & \\
\hline Yes & 14.9 & $20 \cdot 0$ & \\
\hline $\mathrm{CHD}(\%)$ & $n 68$ & $n 64$ & 1.00 \\
\hline No & $95 \cdot 6$ & $45 \cdot 3$ & \\
\hline Yes & 4.4 & $4 \cdot 7$ & \\
\hline Hypertension (\%) & $n 69$ & $n 65$ & $<0.01$ \\
\hline No & $63 \cdot 8$ & 38.5 & \\
\hline Yes & $36 \cdot 2$ & 61.5 & \\
\hline Family history of prostate cancer (\%) & $n 61$ & $n 41$ & 0.09 \\
\hline No & $90 \cdot 2$ & $78 \cdot 1$ & \\
\hline Yes & $9 \cdot 8$ & $22 \cdot 0$ & \\
\hline Serum PSA (ng/ml) & $n 69$ & $n 65$ & \\
\hline Normal $(<4)$ & $n 33$ & & \\
\hline Median & $1 \cdot 1$ & - & \\
\hline 25th-75th percentile & $0 \cdot 8-2 \cdot 0$ & - & \\
\hline Elevated $(\geq 4)$ & $n 36$ & $n 65$ & \\
\hline Median & $8 \cdot 0$ & $6 \cdot 7$ & 0.84 \\
\hline 25th-75th percentile & $5 \cdot 1-11 \cdot 2$ & $5 \cdot 4-10 \cdot 4$ & \\
\hline
\end{tabular}

PSA, prostate-specific antigen.

* $\leq 11$ years includes 12 th grade with no diploma for NHANES men.

As for the covariates, there were no differences in serum carotenoid levels by age group and hypertension status within each group of men (Tables 2 and 3). For BMI, there was no statistically significant difference in serum carotenoid levels in AC Tobagonian and AA men, except for serum retinol levels in AA men where the median level increased from underweight/ normal-weight men $(0.55 \mu \mathrm{g} / \mathrm{ml})$ to overweight men $(0.67 \mu \mathrm{g} /$ $\mathrm{ml}$ ) (Table 3). For ever smoked cigarettes, serum $\alpha$ - and $\beta$-carotenes and $\beta$-cryptoxanthin levels were statistically significantly lower among AC Tobagonian smokers compared with non-smokers $(P \leq 0.04)$ (Table 2$)$. Serum lycopene, $\beta$-carotenes and $\beta$-cryptoxanthin levels were statistically significantly lower among AA smokers compared with nonsmokers $(P \leq 0.03)$ (Table 3). As for education, AC Tobagonian men with $\geq 12$ years of education had statistically significantly higher serum lycopene levels compared with AC Tobagonian men with $\leq 11$ years of education. AA men with $\geq 12$ years of education had statistically significantly higher serum $\alpha$-carotene and $\beta$-cryptoxanthin compared with AA men with $\leq 11$ years of education. 

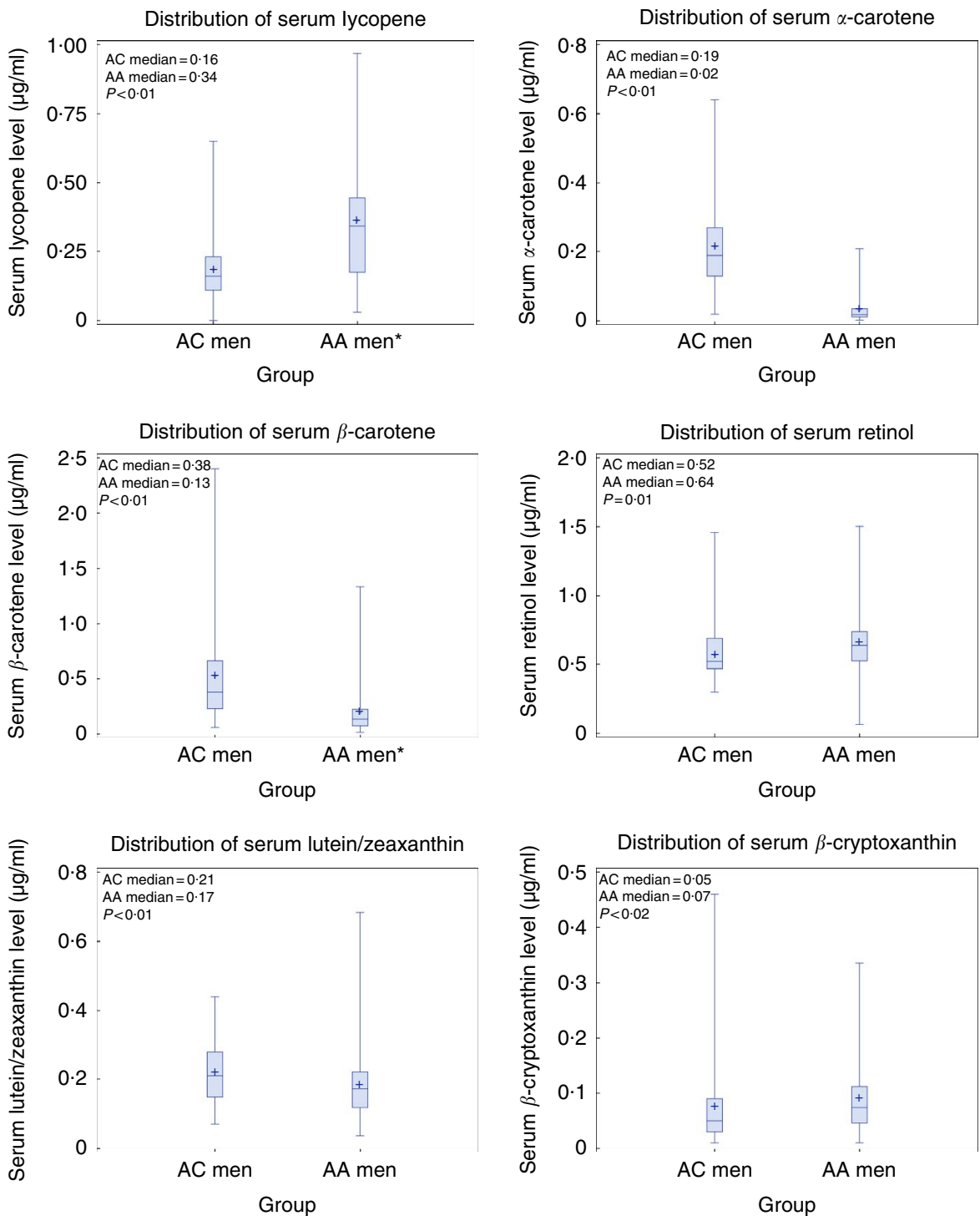

Fig. 1. Median serum carotenoid and retinol levels in African-Caribbean (AC) Tobagonian men ( $n$ 69) compared with African-American (AA) National Health and Nutrition Examination Survey men $(n 65) .+$ on box plot, mean. * Sample size is less than sixty-five men among AA (serum lycopene $=$ forty-two men and $\beta$-carotene $=$ sixty-two men).

After adjusting for age, BMI, ever smoked cigarettes, education and hypertension, AC Tobagonian men were associated with lower serum lycopene and retinol levels, and higher serum $\alpha$ - and $\beta$-carotenes and lutein/zeaxanthin levels compared with AA men (Table 4). Among men with elevated PSA, AC Tobagonian men were associated with lower serum lycopene, and higher serum $\alpha$ - and $\beta$-carotenes and lutein/zeaxanthin levels compared with AA men, after adjusting for confounding factors (Table 4).

\section{Discussion}

To our knowledge, this was the first study to compare serum carotenoid and retinols levels between different black populations at risk for prostate cancer. We found that AC Tobagonian men were associated with lower levels of serum lycopene and retinol, but higher levels of serum $\alpha$ - and $\beta$-carotenes and lutein/zeaxanthin, compared with AA men. Among men with an elevated serum PSA, the association found between these serum carotenoids and ethnicity remained, except for serum retinol, confirming their difference between these two groups of men. Even though AC Tobagonian men had lower serum lycopene levels, they had a higher dietary intake of lycopene compared with AA men; this finding may explain the low correlation observed between dietary intake and circulating lycopene levels among AC Tobagonian men. Because the present study was a descriptive study, the reasons for the difference in serum carotenoid and retinol levels between these two groups of men as well as the relationship observed between dietary lycopene intake and serum lycopene level were not investigated. Nevertheless, circulating carotenoid biomarkers have been suggested to be a better measurement of levels in tissue 

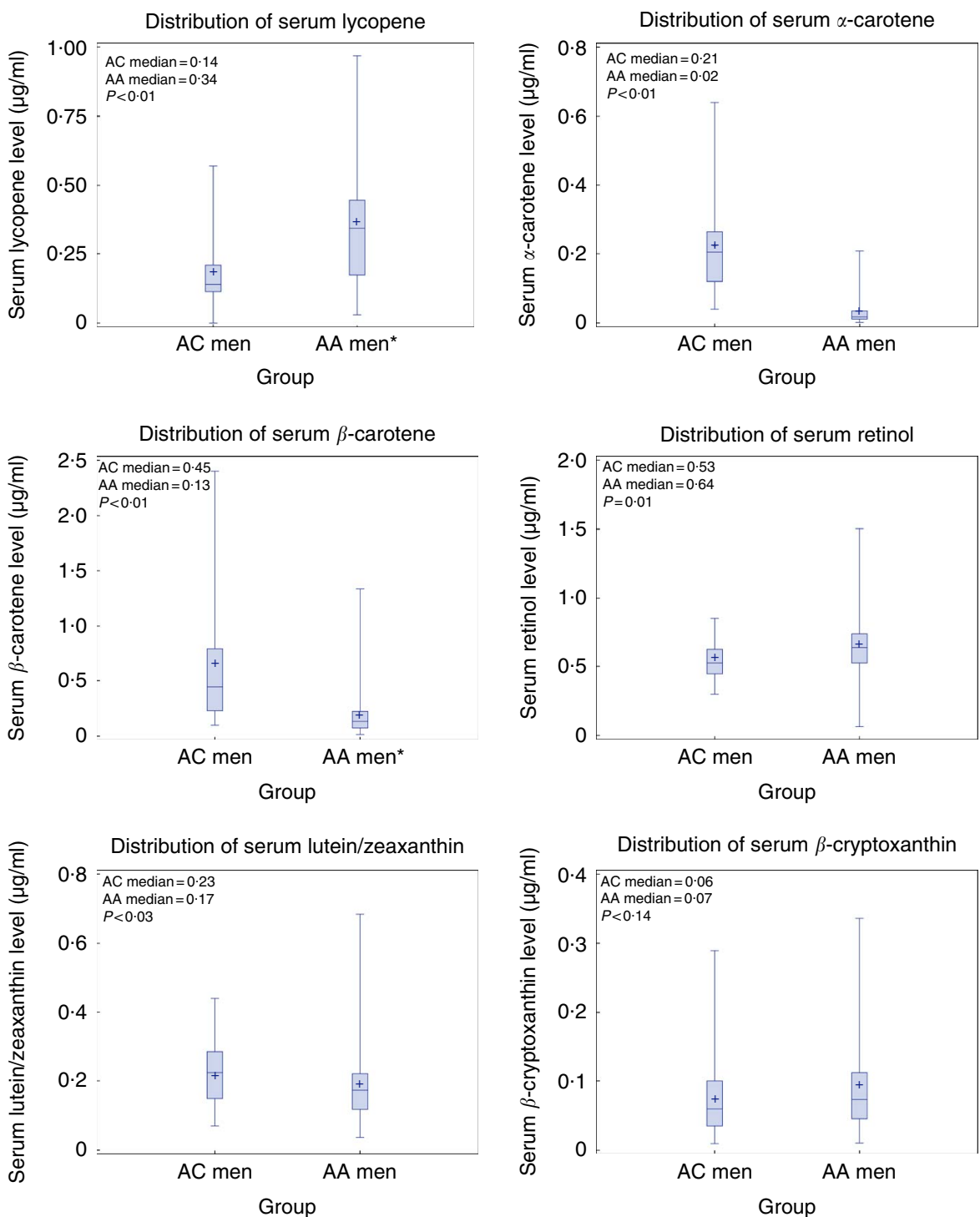

Fig. 2. Median serum carotenoid and retinol levels in African-Caribbean (AC) Tobagonian men with elevated serum prostate-specific antigen (PSA) ( $n$ 36) compared with African-American (AA) National Health and Nutrition Examination Survey men with elevated serum PSA ( $n 65)$. + on box plot, mean. *Sample size is less than sixty-five men among $A A$ (serum lycopene $=$ forty-two men and $\beta$-carotene $=$ sixty-two men).

than dietary intake ${ }^{(21)}$, which implies that serum carotenoid may be an appropriate biomarker for assessing their influence on cancer risk.

Previous studies have shown dietary intake and higher circulating levels of lycopene associated with decreased risk for prostate cancer $^{(3,4,22,23)}$ and aggressive disease ${ }^{(7,9,24,25)}$. AA men have been reported to have lower serum lycopene levels compared with US white men ${ }^{(24)}$. However, it is not known whether these lower levels in AA men explain the higher prostate cancer incidence and more aggressive disease observed among them compared with US white men. In the present study, AC Tobagonian men were associated with lower serum lycopene levels compared with AA men. These lower circulating lycopene levels among AC Tobagonian men are consistent when compared with levels reported in other AA study populations from previous studies ${ }^{(26,27)}$; these lower levels support our study's hypothesis. One possible explanation for the difference in serum lycopene levels could be that $\mathrm{AC}$ Tobagonian men differ in the types (raw or cooked) and quantity of lycopene foods consumed such as tomato and tomato-based products, factors that may influence bioavailability, in comparison with AA men. Even though AC Tobagonian and AA men are descendants of West Africa, there may be genetic differences between them, including low admixture which has been documented in the Tobagonian populations ${ }^{(28)}$ - which may explain the difference in serum lycopene levels ${ }^{(29)}$. Studies have found genetic variants in humans and in foods associated with lycopene bioavailability ${ }^{(30)}$. In addition, health status may influence lycopene bioavailability ${ }^{(29)}$. More than half of AC Tobagonian men had HGPIN and/or atypia, conditions considered precursors to prostate cancer ${ }^{(31,32)}$. These prostatic conditions may reflect the lower serum 
Table 2. Baseline serum carotenoid and retinol levels by covariates among African-Caribbean Tobagonian men (Medians with their standard errors)

\begin{tabular}{|c|c|c|c|c|c|c|c|c|c|c|c|c|c|}
\hline \multirow[b]{3}{*}{ Characteristics } & \multirow[b]{3}{*}{$n$} & \multicolumn{12}{|c|}{ Levels $(\mu \mathrm{g} / \mathrm{ml})$} \\
\hline & & \multicolumn{2}{|c|}{ Lycopene } & \multicolumn{2}{|c|}{$a$-Carotene } & \multicolumn{2}{|c|}{$\beta$-Carotene } & \multicolumn{2}{|c|}{ Retinol } & \multicolumn{2}{|c|}{ Lutein/zeaxanthin } & \multicolumn{2}{|c|}{$\beta$-Cryptoxanthin } \\
\hline & & Median & SE & Median & SE & Median & SE & Median & SE & Median & SE & Median & SE \\
\hline \multicolumn{14}{|l|}{ Age group (years) } \\
\hline $40-49$ & 8 & 0.18 & 0.03 & 0.16 & 0.04 & 0.34 & 0.09 & 0.52 & 0.05 & 0.20 & 0.02 & 0.04 & 0.01 \\
\hline $50-59$ & 20 & 0.16 & 0.02 & 0.16 & 0.02 & 0.33 & 0.05 & 0.51 & 0.05 & 0.22 & 0.02 & 0.05 & 0.01 \\
\hline $60-69$ & 25 & 0.17 & 0.03 & 0.22 & 0.02 & 0.41 & 0.11 & 0.52 & 0.03 & 0.24 & 0.02 & 0.06 & 0.02 \\
\hline $70-79$ & 16 & 0.12 & 0.02 & 0.20 & 0.04 & 0.45 & 0.14 & 0.56 & 0.03 & $0 \cdot 20$ & 0.02 & 0.05 & 0.02 \\
\hline$P$ & & \multicolumn{2}{|c|}{0.21} & \multicolumn{2}{|c|}{0.18} & \multicolumn{2}{|c|}{0.83} & \multicolumn{2}{|c|}{0.86} & \multicolumn{2}{|c|}{0.53} & \multicolumn{2}{|c|}{0.66} \\
\hline \multicolumn{14}{|l|}{ BMI $\left(\mathrm{kg} / \mathrm{m}^{2}\right)$} \\
\hline Underweight /normal $(<25)$ & 20 & 0.18 & 0.04 & 0.23 & 0.03 & 0.45 & 0.11 & 0.51 & 0.03 & 0.22 & 0.02 & 0.06 & 0.02 \\
\hline Overweight (25-29.9) & 33 & 0.14 & 0.02 & 0.16 & 0.02 & 0.38 & 0.08 & 0.53 & 0.03 & 0.22 & 0.01 & 0.05 & 0.01 \\
\hline Obese $(\geq 30)$ & 16 & 0.14 & 0.02 & $0 \cdot 20$ & 0.03 & $0 \cdot 26$ & 0.09 & 0.54 & 0.03 & 0.19 & 0.02 & 0.04 & 0.01 \\
\hline$P$ & & \multicolumn{2}{|c|}{0.64} & \multicolumn{2}{|c|}{0.39} & \multicolumn{2}{|c|}{0.10} & \multicolumn{2}{|c|}{0.87} & \multicolumn{2}{|c|}{0.57} & \multicolumn{2}{|c|}{0.73} \\
\hline \multicolumn{14}{|l|}{ Ever smoked cigarettes } \\
\hline No & 40 & 0.16 & 0.02 & 0.22 & 0.02 & 0.45 & 0.08 & 0.53 & 0.02 & 0.23 & 0.01 & 0.07 & 0.01 \\
\hline Yes & 29 & 0.16 & 0.02 & 0.14 & 0.02 & 0.30 & 0.06 & 0.51 & 0.04 & 0.20 & 0.02 & 0.05 & 0.00 \\
\hline$P$ & & \multicolumn{2}{|c|}{0.61} & \multicolumn{2}{|c|}{$<0.01$} & \multicolumn{2}{|c|}{0.01} & \multicolumn{2}{|c|}{0.75} & \multicolumn{2}{|c|}{0.36} & 0 & \\
\hline Education & & & & & & & & & & & & & \\
\hline$\leq 11$ years & 52 & 0.14 & 0.02 & 0.20 & 0.02 & 0.43 & 0.07 & 0.51 & 0.02 & 0.22 & 0.01 & 0.05 & 0.01 \\
\hline$\geq 12$ years & 17 & 0.24 & 0.02 & 0.19 & 0.02 & 0.31 & 0.09 & 0.53 & 0.03 & 0.18 & 0.02 & 0.05 & 0.02 \\
\hline$P$ & & 0.0 & & 0.8 & & 0.1 & & 0.2 & & & & 0 & \\
\hline Hypertension & & & & & & & & & & & & & \\
\hline No & 44 & 0.17 & 0.02 & 0.18 & 0.02 & 0.39 & 0.07 & 0.53 & 0.03 & 0.21 & 0.01 & 0.06 & 0.01 \\
\hline Yes & 25 & 0.12 & 0.02 & 0.21 & 0.02 & 0.38 & 0.09 & 0.50 & 0.03 & 0.23 & 0.02 & 0.04 & 0.02 \\
\hline$P$ & & 0.0 & & 0.9 & & 0.8 & & 0.2 & & & & 0 & \\
\hline
\end{tabular}

Table 3. Baseline serum carotenoid and retinol levels by covariates among African-American National Health and Nutrition Examination Survey (NHANES) men

(Medians with their standard errors)

\begin{tabular}{|c|c|c|c|c|c|c|c|c|c|c|c|c|c|}
\hline \multirow[b]{3}{*}{ Characteristics } & \multirow[b]{3}{*}{$n$} & \multicolumn{12}{|c|}{ Levels $(\mu \mathrm{g} / \mathrm{ml})$} \\
\hline & & \multicolumn{2}{|c|}{ Lycopene† } & \multicolumn{2}{|c|}{ a-Carotene } & \multicolumn{2}{|c|}{$\beta$-Carotene $\dagger$} & \multicolumn{2}{|c|}{ Retinol } & \multicolumn{2}{|c|}{ Lutein/zeaxanthin } & \multicolumn{2}{|c|}{$\beta$-Cryptoxanthin } \\
\hline & & Median & SE & Median & SE & Median & SE & Median & SE & Median & SE & Median & SE \\
\hline \multicolumn{14}{|l|}{ Age group (years) } \\
\hline $40-49$ & 2 & 0.41 & 0.03 & 0.01 & 0.01 & $0 \cdot 24$ & $0 \cdot 21$ & 0.62 & $0 \cdot 12$ & 0.24 & 0.14 & 0.09 & 0.04 \\
\hline $50-59$ & 13 & 0.40 & 0.09 & 0.02 & 0.01 & 0.08 & 0.03 & 0.65 & 0.08 & 0.14 & 0.02 & 0.07 & 0.02 \\
\hline $60-69$ & 26 & 0.35 & 0.05 & 0.02 & 0.01 & $0 \cdot 14$ & 0.03 & 0.64 & 0.05 & $0 \cdot 18$ & 0.03 & 0.08 & 0.02 \\
\hline $70-80$ & 24 & $0 \cdot 21$ & 0.05 & 0.02 & 0.01 & $0 \cdot 20$ & 0.06 & 0.58 & 0.03 & 0.18 & 0.01 & 0.07 & 0.01 \\
\hline$P$ & & \multicolumn{2}{|c|}{0.10} & \multicolumn{2}{|c|}{0.95} & \multicolumn{2}{|c|}{0.17} & \multicolumn{2}{|c|}{0.72} & \multicolumn{2}{|c|}{0.51} & \multicolumn{2}{|c|}{0.25} \\
\hline \multicolumn{14}{|l|}{ BMI $\left(\mathrm{kg} / \mathrm{m}^{2}\right)$} \\
\hline Underweight /normal $(<25)$ & 19 & 0.30 & 0.05 & 0.02 & 0.01 & 0.09 & 0.04 & 0.55 & 0.04 & $0 \cdot 16$ & 0.03 & 0.06 & 0.01 \\
\hline Overweight (25-29.9) & 23 & 0.35 & 0.06 & 0.02 & 0.01 & $0 \cdot 18$ & 0.06 & 0.64 & 0.04 & $0 \cdot 16$ & 0.02 & 0.08 & 0.01 \\
\hline Obese $(\geq 30)$ & 22 & 0.38 & 0.06 & 0.02 & 0.01 & 0.13 & 0.03 & 0.67 & 0.06 & 0.18 & 0.02 & 0.08 & 0.02 \\
\hline$P$ & & \multicolumn{2}{|c|}{0.40} & \multicolumn{2}{|c|}{0.90} & \multicolumn{2}{|c|}{0.23} & \multicolumn{2}{|c|}{0.04} & \multicolumn{2}{|c|}{0.65} & \multicolumn{2}{|c|}{0.48} \\
\hline \multicolumn{14}{|l|}{ Ever smoked cigarettes } \\
\hline No & 27 & 0.40 & 0.05 & 0.02 & 0.01 & $0 \cdot 20$ & 0.03 & 0.65 & 0.04 & $0 \cdot 18$ & 0.02 & 0.08 & 0.02 \\
\hline Yes & 38 & 0.30 & 0.03 & 0.02 & 0.00 & 0.09 & 0.04 & 0.62 & 0.04 & 0.16 & 0.01 & 0.07 & 0.01 \\
\hline$P$ & & \multicolumn{2}{|c|}{0.01} & \multicolumn{2}{|c|}{0.07} & \multicolumn{2}{|c|}{$<0.01$} & \multicolumn{2}{|c|}{0.22} & \multicolumn{2}{|c|}{0.21} & & \\
\hline Education $\ddagger$ & & & & & & & & & & & & & \\
\hline$\leq 11$ years & 33 & 0.29 & 0.05 & 0.01 & 0.01 & 0.13 & 0.05 & 0.63 & 0.04 & 0.17 & 0.02 & 0.06 & 0.01 \\
\hline$\geq 12$ years & 32 & 0.38 & 0.05 & 0.02 & 0.01 & 0.18 & 0.03 & 0.65 & 0.04 & 0.17 & 0.02 & 0.09 & 0.01 \\
\hline$P$ & & 0. & & 0.0 & & 0 & & 0.5 & & & & $<0$ & \\
\hline Hypertension & & & & & & & & & & & & & \\
\hline No & 25 & 0.38 & 0.05 & 0.02 & 0.01 & 0.08 & 0.02 & 0.60 & 0.04 & 0.14 & 0.01 & 0.07 & 0.01 \\
\hline Yes & 40 & 0.32 & 0.04 & 0.02 & 0.01 & 0.16 & 0.04 & 0.65 & 0.04 & 0.18 & 0.02 & 0.08 & 0.01 \\
\hline$P$ & & 0 & & 1.0 & & 0 & & 0.1 & & & & & \\
\hline
\end{tabular}

† Sample size is less than the total number of men in the sub-groups.

$\ddagger \leq 11$ years includes 12 th grade with no diploma for NHANES men. 
Table 4. Association of serum carotenoid and retinol levels $(\mu \mathrm{g} / \mathrm{ml})$ in African-Caribbean (AC) Tobagonian men compared with African-American (AA) National Health and Nutrition Examination Survey (NHANES) men, adjusted for confounding factors* (Quartile regression estimates with their standard errors and 95\% confidence intervals)

\begin{tabular}{|c|c|c|c|c|c|c|c|c|}
\hline \multirow[b]{2}{*}{ Models } & \multicolumn{4}{|c|}{ Total population (69 AC men v. 64 AA men) } & \multicolumn{4}{|c|}{ Elevated serum PSA (36 AC men v. 64 AA men) } \\
\hline & Estimate & SE & $95 \% \mathrm{Cl}$ & $P$ & Estimate & SE & $95 \% \mathrm{Cl}$ & $P$ \\
\hline Lycopene & -0.16 & 0.04 & $-0.23,-0.08$ & $<0.01$ & -0.17 & 0.03 & $-0.23,-0.10$ & $<0.01$ \\
\hline$a$-Carotene & 0.17 & 0.01 & $0.15,0.20$ & $<0.01$ & 0.18 & 0.02 & $0.14,0.22$ & $<0.01$ \\
\hline$\beta$-Carotene & 0.20 & 0.04 & $0.11,0.29$ & $<0.01$ & 0.30 & 0.08 & $0.13,0.46$ & $<0.01$ \\
\hline Retinol & -0.09 & 0.04 & $-0.17,-0.01$ & 0.03 & -0.09 & 0.04 & $-0.17,-0.01$ & 0.06 \\
\hline Lutein/zeaxanthin & 0.06 & 0.02 & $0.02,0.09$ & 0.01 & 0.04 & 0.02 & $-0.01,0.08$ & 0.02 \\
\hline$\beta$-Cryptoxanthin & -0.02 & 0.01 & $-0.04,0.00$ & $0 \cdot 10$ & -0.01 & 0.01 & $-0.03,0.02$ & 0.59 \\
\hline
\end{tabular}

lycopene levels observed among AC Tobagonian men compared with AA men with elevated serum PSA. On the basis of this present study, it is not known whether lower serum lycopene levels found among AC Tobagonian men explain the higher age-specific prostate cancer prevalence reported among them compared with SEER AA men ${ }^{(16,18)}$; therefore, further investigation is warranted.

The correlation between dietary intake of lycopene and serum lycopene levels differed between AC Tobagonian and AA men. There was a lower correlation observed for AC Tobagonian $\left(r_{\mathrm{s}} 0 \cdot 15\right)$ compared with AA men $\left(r_{\mathrm{s}} 0 \cdot 58\right)$. Among AA populations in previous studies, correlations between dietary intake and circulating lycopene levels ranged from 0.06 to 0.37 , depending on whether dietary intake was determined from an FFQ and/or a 24-h dietary recall questionnaire $^{(26,27,33,34)}$. For AC Tobagonian men, an FFQ was administered as opposed to a 24-h dietary recall questionnaire that was used among AA NHANES men. Some studies have reported higher correlations among AA populations using the 24-h dietary recall questionnaire compared with the $\mathrm{FFQ}^{(33,34)}$, which may suggest that the 24-h dietary recall questionnaire is a better measurement of dietary intake or a more accurate representation of circulating lycopene levels. This difference in dietary assessment for AC Tobagonian men compared with AA men may explain the difference in correlation observed between dietary intake and serum lycopene levels. Other possible reasons for this correlation difference may be attributed to factors such as age, genetic influences, difference in bioavailability of lycopene within individuals or laboratory error in assessing circulating lycopene levels ${ }^{(33,34)}$

Overall, AC Tobagonian men had statistically significantly lower serum retinol levels compared with AA men. Retinol is found in cod liver oil, liver, butter, eggs and dairy products. Studies suggest that retinol can inhibit cellular proliferation and differentiation and induce apoptosis ${ }^{(5,15)}$, mechanisms that affect carcinogenesis. For prostate cancer, most studies have reported either no associations or inverse associations between retinol dietary intake and higher circulating levels and prostate cancer $^{(4-7,9,35-37)}$. In the present study, there was no statistically significant association between serum retinol levels and black ethnicity among men with elevated serum PSA. This finding may be due to the small sample size or to the fact that there was no difference in serum retinol levels between these two groups of men with elevated serum PSA.

AC Tobagonian men had greater serum $\alpha$ - and $\beta$-carotene levels compared with AA men. $\alpha$-Carotene and $\beta$-carotene are found in many of the same vegetables such as carrots, sweet potatoes and green leafy vegetables such as spinach and collard greens as well as in fruits such as mangoes. Most studies have found an inverse relationship as well as no association between prostate cancer risk and higher $\alpha$-carotene ${ }^{(4,8,37-39)}$ and $\beta$-carotene ${ }^{(4,5,8,35-38,40,41)}$ intakes and higher circulating levels. Even though higher serum levels of $\alpha$ - and $\beta$-carotenes among AC Tobagonian men did not support our study's hypothesis, these higher levels could be due to the fact that Tobagonian men consumed foods higher in $\alpha$ - and $\beta$-carotenes in comparison with AA men, in particular around the time of enrolment (July-August 2003) in comparison with AA NHANES men who were recruited throughout the year. Circulating $\alpha$ - and $\beta$-carotene levels have been found to have a higher correlation with dietary intake compared with lycopene among AA men ${ }^{(26,27,33,34)}$, indicating that these circulating levels may be a better reflection of diet in comparison with circulating lycopene. In addition, cigarette smokers had lower $\alpha$ - and $\beta$-carotene levels among AC Tobagonian men and lower $\beta$-carotene levels among AA men compared with non-smokers. Oxidants from cigarette smoke are known to affect carotenoid levels, causing lower levels ${ }^{(37)}$. Cigarette smoking did not differ between AC Tobagonian and AA men; therefore, it may not explain the higher levels of $\alpha$ - and $\beta$-carotenes observed among AC Tobagonian men compared with AA men.

AC Tobagonian men had higher serum lutein/zeaxanthin levels, carotenoids that are often examined together, compared with AA men; this finding did not support our study's hypothesis. Lutein and zeaxanthin, found in dark-green leafy vegetables, are known to reduce the risk for age-related macular degeneration. As for their relationship with prostate cancer, no associations and inverse associations were found between these carotenoids individually and collectively with prostate cancer in previous studies ${ }^{(4,8,37,42)}$. In the present study, differences in serum levels between AC Tobagonian and AA men could be due to dietary intake or factors that influence the bioavailability of the carotenoids. 
In the present study, there were limitations. In the lycopene supplementation clinical trial, dietary intake was collected for only lycopene but not for the other carotenoids and retinol among Tobagonian men. There was a small sample size for both groups of men. There were missing data for both groups of men such as the following: (1) total serum lycopene was not collected in NHANES 2001-2002; (2) there was no HGPIN and atypia data on NHANES men, and (3) serum/plasma cholesterol data, a covariate, was not collected for Tobagonian men. Data such as smoking and education were collected differently for both groups of men. Dietary lycopene intake among AA NHANES men did not account for dietary lycopene-containing supplements, which may have underestimated their total dietary lycopene intake. However, among Tobagonian men, there was only one man who reported supplement use. Finally, there were two different laboratories used to analyse serum specimens of Tobagonian and NHANES men. These laboratories used the same standards based on SRM for serum carotenoid testing but different methods for total serum PSA determination; therefore, there was a chance of variability in laboratory results ${ }^{(43)}$. However, a study found that serum PSA assays such as the ones used in the present study agreed well ${ }^{(44)}$.

In conclusion, the lower levels of serum lycopene and retinol, but higher levels of serum $\alpha$ - and $\beta$-carotenes and lutein/ zeaxanthin among AC Tobagonian men compared with AA men may be attributed to dietary intake, genetics, and/or other factors that influence bioavailability of carotenoids and retinol. Prospective studies are warranted that investigate whether differences in carotenoids and retinol between AC Tobagonian and AA men influence prostate cancer risk.

\section{Acknowledgements}

The study was supported in-kind by the Division of Health and Social Services, Tobago House of Assembly.

The study was supported, in part, by funding received from the Pennsylvania State University College of Medicine (A. C. M., J. Raman, and J. Richie), the University of Pittsburgh (C. H. B.), the US Department of Defense (C. H. B. and A. L. P.; DAMD 17-99-1-9015) and the National Institutes of Health (C. H. B. and A. L. P.; R01 CA84950 and R01 CA84950S1).

A. C. M. participated in study design, performed data analysis and wrote the manuscript. C. H. B. and A. L. P. acquired data and provided study coordination. A. C. M., C. H. B., J. Raman and J. Richie participated in data interpretation. A. C. M., C. H. B., J. Raman and J. Richie helped to revise the final manuscript.

The authors declare that there are no conflicts of interest.

\section{References}

1. Ferlay J, Soerjomataram I, Ervik M, et al. (2013) Cancer incidence and mortality worldwide, Globocan 2012 v1.0, IARC CancerBase No. 11. Lyon: International Agency for Research on Cancer.

2. American Cancer Society (2016) Cancer Facts \& Figures 2016. Atlanta: American Cancer Society.

3. Etminan M, Takkouche B \& Caamano-Isorna F (2004) The role of tomato products and lycopene in the prevention of prostate cancer: a meta-analysis of observational studies. Cancer Epidemiol Biomarkers Prev 13, 340-345.

4. Jian L, Du CJ, Lee AH, et al. (2005) Do dietary lycopene and other carotenoids protect against prostate cancer? Int J Cancer 113, 1010-1014.

5. Nash SH, Till C, Song X, et al. (2015) Serum retinol and carotenoid concentrations and prostate cancer risk: results from the Prostate Cancer Prevention Trial. Cancer Epidemiol Biomarkers Prev 24, 1507-1515.

6. Mondul AM, Watters JL, Mannisto S, et al. (2011) Serum retinol and risk of prostate cancer. Am J Epidemiol 173, 813-821.

7. Gann PH, Ma J, Giovannucci E, et al. (1999) Lower prostate cancer risk in men with elevated plasma lycopene levels: results of a prospective analysis. Cancer Res 59, $1225-1230$

8. Wu K, Erdman JW Jr, Schwartz SJ, et al. (2004) Plasma and dietary carotenoids, and the risk of prostate cancer: a nested casecontrol study. Cancer Epidemiol Biomarkers Prev 13, 260-269.

9. Key TJ, Appleby PN, Travis RC, et al. (2015) Carotenoids, retinol, tocopherols, and prostate cancer risk: pooled analysis of 15 studies. Am J Clin Nutr 102, 1142-1157.

10. Coates RJ, Weiss NS, Daling JR, et al. (1988) Serum levels of selenium and retinol and the subsequent risk of cancer. $A m J$ Epidemiol 128, 515-523.

11. Ripple MO, Henry WF, Rago RP, et al. (1997) Prooxidantantioxidant shift induced by androgen treatment of human prostate carcinoma cells. J Natl Cancer Inst 89, 40-48.

12. Di Mascio P, Kaiser S \& Sies H (1989) Lycopene as the most efficient biological carotenoid singlet oxygen quencher. Arch Biochem Biophys 274, 532-538.

13. Conn PF, Schalch W \& Truscott TG (1991) The singlet oxygen and carotenoid interaction. J Photochem Photobiol B 11, 41-47.

14. Stahl W, Junghans A, de Boer B, et al. (1998) Carotenoid mixtures protect multilamellar liposomes against oxidative damage: synergistic effects of lycopene and lutein. FEBS Lett 427, 305-308.

15. Altucci L, Rossin A, Raffelsberger W, et al. (2001) Retinoic acid-induced apoptosis in leukemia cells is mediated by paracrine action of tumor-selective death ligand TRAIL. Nat Med 7, 680-686.

16. Patrick AL, Bunker CH, Nelson JB, et al. (2015) Argument for prostate cancer screening in populations of African-Caribbean origin. BJU Int 116, 507-508.

17. Bunker $\mathrm{CH}$, Patrick AL, Konety BR, et al. (2002) High prevalence of screening-detected prostate cancer among Afro-Caribbeans: the Tobago Prostate Cancer Survey. Cancer Epidemiol Biomarkers Prev 11, 726-729.

18. Ries L, Eisner M, Kosary C, et al. (2004) SEER Cancer Statistics Review, 1975-2002. https://seer.cancer.gov/archive/ csr/1975_2002/ (accessed March 2017).

19. Bunker $\mathrm{CH}$, McDonald AC, Evans RW, et al. (2007) A randomized trial of lycopene supplementation in Tobago men with high prostate cancer risk. Nutr Cancer 57, 130-137.

20. Centers for Disease Control and Prevention (2008) Laboratory procedure manual. Fat soluble micronutrients (vitamins A, E and carotenoids). http://www.cdc.gov/nchs/data/nhanes/nhanes_03_ 04/145vit_c_met_vitae_carotenoids.pdf (accessed July 2016).

21. Tamimi RM, Hankinson SE, Campos H, et al. (2005) Plasma carotenoids, retinol, and tocopherols and risk of breast cancer. Am J Epidemiol 161, 153-160.

22. Kucuk O, Sarkar FH, Sakr W, et al. (2001) Phase II randomized clinical trial of lycopene supplementation before radical prostatectomy. Cancer Epidemiol Biomarkers Prev 10, 861-868.

23. Chen L, Stacewicz-Sapuntzakis M, Duncan C, et al. (2001) Oxidative DNA damage in prostate cancer patients consuming tomato sauce-based entrees as a whole-food intervention. J Natl Cancer Inst 93, 1872-1879. 
24. Vogt TM, Mayne ST, Graubard BI, et al. (2002) Serum lycopene, other serum carotenoids, and risk of prostate cancer in US Blacks and Whites. Am J Epidemiol 155, 1023-1032.

25. Zu K, Mucci L, Rosner BA, et al. (2014) Dietary lycopene, angiogenesis, and prostate cancer: a prospective study in the prostate-specific antigen era. J Natl Cancer Inst 106, dit430.

26. Arab L, Cambou MC, Craft N, et al. (2011) Racial differences in correlations between reported dietary intakes of carotenoids and their concentration biomarkers. Am I Clin Nutr 93, 1102-1108.

27. Signorello LB, Buchowski MS, Cai Q, et al. (2010) Biochemical validation of food frequency questionnaire-estimated carotenoid, alpha-tocopherol, and folate intakes among African Americans and non-Hispanic Whites in the Southern Community Cohort Study. Am J Epidemiol 171, 488-497.

28. Miljkovic-Gacic I, Ferrell RE, Patrick AL, et al. (2005) Estimates of African, European and Native American ancestry in Afro-Caribbean men on the island of Tobago. Hum Hered $\mathbf{6 0}$, 129-133.

29. Fiedor J \& Burda K (2014) Potential role of carotenoids as antioxidants in human health and disease. Nutrients 6, 466-488.

30. Borel P, Desmarchelier C, Nowicki M, et al. (2015) Lycopene bioavailability is associated with a combination of genetic variants. Free Radic Biol Med 83, 238-244.

31. Moore CK, Karikehalli S, Nazeer T, et al. (2005) Prognostic significance of high grade prostatic intraepithelial neoplasia and atypical small acinar proliferation in the contemporary era. J Urol 173, 70-72.

32. Schlesinger C, Bostwick DG \& Iczkowski KA (2005) Highgrade prostatic intraepithelial neoplasia and atypical small acinar proliferation: predictive value for cancer in current practice. Am J Surg Pathol 29, 1201-1207.

33. Talegawkar SA, Johnson EJ, Carithers TC, et al. (2008) Carotenoid intakes, assessed by food-frequency questionnaires (FFQs), are associated with serum carotenoid concentrations in the Jackson Heart Study: validation of the Jackson Heart Study Delta NIRI Adult FFQs. Public Health Nutr 11, 989-997.

34. Fraser GE \& Jaceldo-Siegl K (2016) Biomarkers of dietary intake are correlated with corresponding measures from repeated dietary recalls and food-frequency questionnaires in the Adventist Health Study-2. 146, 586-594.

35. Hsing AW, McLaughlin JK, Schuman LM, et al. (1990) Diet, tobacco use, and fatal prostate cancer: results from the Lutheran Brotherhood Cohort Study. Cancer Res 50, 6836-6840

36. Oishi K, Okada K, Yoshida O, et al. (1988) A case-control study of prostatic cancer with reference to dietary habits. Prostate 12, 179-190.

37. Goodman GE, Schaffer S, Omenn GS, et al. (2003) The association between lung and prostate cancer risk, and serum micronutrients: results and lessons learned from beta-carotene and retinol efficacy trial. Cancer Epidemiol Biomarkers Prev 12, 518-526.

38. Umesawa M, Iso H, Mikami K, et al. (2014) Relationship between vegetable and carotene intake and risk of prostate cancer: the JACC study. Br J Cancer 110, 792-796.

39. Norrish AE, Jackson RT, Sharpe SJ, et al. (2000) Prostate cancer and dietary carotenoids. Am J Epidemiol 151, $119-123$.

40. Ohno Y, Yoshida O, Oishi K, et al. (1988) Dietary betacarotene and cancer of the prostate: a case-control study in Kyoto, Japan. Cancer Res 48, 1331-1336.

41. Mettlin C, Selenskas S, Natarajan N, et al. (1989) Beta-carotene and animal fats and their relationship to prostate cancer risk. A case-control study. Cancer 64, 605-612.

42. Giovannucci E, Ascherio A, Rimm EB, et al. (1995) Intake of carotenoids and retinol in relation to risk of prostate cancer. I Natl Cancer Inst 87, 1767-1776.

43. Stephan C, Kramer J, Meyer HA, et al. (2007) Different prostate-specific antigen assays give different results on the same blood sample: an obstacle to recommending uniform limits for prostate biopsies. BJU Int 99, 1427-1431.

44. Kort SA, Martens F, Vanpoucke H, et al. (2006) Comparison of 6 automated assays for total and free prostate-specific antigen with special reference to their reactivity toward the WHO 96/670 reference preparation. Clin Chem 52, $1568-1574$ 